\title{
A Pattern Language for Social Field Shifts:
}

\section{Cultivating Embodied and Perceptual Capacities of Social Groups through Aesthetics and Social Field Archetypes}

\author{
Arawana Hayashi \\ Presencing Institute, Boston, USA \\ hayashi@presencing.com \\ Ricardo D. Gonçalves \\ Art Design \& Architecture, Monash University, Melbourne, Australia \\ Ricardo.DutraGoncalves@monash.edu
}

\begin{abstract}
The complex systemic issues of today, including climate change, racism, social inequality, mental health crisis, call for new ways of engaging the heart (feeling), mind (thinking), and will (doing) to actually change deep-rooted behaviors. To develop these new ways of engaging, one must learn how to cultivate first, one's interior condition (the inner place from which we operate) and second, one's capacities to co-create with others the exterior conditions for healthy social relationships. In this paper, we claim that by living in a body we are embodied and that wisdom lives in a holistic knowing that includes embodied intelligence. We argue that to address the complex challenges of our times, we must cultivate embodied and perceptual capacities and a language for our embodied experience(s). Over three years of workshops with advanced practitioners of an
\end{abstract}


embodied practice called Social Presencing Theater (SPT), we used embodied activities and design prompts (drawing, photo, video) to surface and make visible social patterns. This has led us to develop a language in the context of social systems change, in particular of social field shifts (i.e., transformations in the relational and felt qualities of our social systems). Through this paper we aim to contribute to social field research by proposing an embodied, visual, and verbal language for social groups to describe and reflect on social field shifts, made up of two parts: first, an aesthetic language to describe social field qualities; and second, three families of social field archetypes to describe social fields.

\section{Keywords}

awareness-based action research, Social Presencing Theater, social fields, design prompts, social arts, phenomenological research

\section{Introduction}

This paper emerged from the collaborative work between a social designer and a choreographer, engaged in contexts of social change-working with applied projects within a network of change makers, leaders, and action researchers known as the Presencing Institute. The institute was founded at the Massachusetts Institute of Technology (Cambridge, US), based on a body of research work on systems thinking (Meadows, 2008; Senge, 1990; Scharmer, 2018). It has developed innovative methods, practices, and inquiries around awareness-based action research (Scharmer \& Kaeufer, 2015). By introducing performance as everyday social-making (Hayashi, 2017; Janevski \& Lax, 2018; Kaufman \& McAdams, 2018; Overlie, 2016) and design as a practice of making visible (Cross, 2006; Grocott, 2010; Hunt, 2012; Kolko, 2011; Mattelmäki, 2005; Schön, 1983) to awareness-based action research, it is our intention to demonstrate new ways of making visible intangible qualities of our social systems and social fields.

\section{The Possibility for Healthy and Thriving Society}

A core foundation of our action research practice is based on the hypothesis that society inherently has the potential for well-being and health. By health, we mean the social and environmental systems' ability to thrive. In this article, we work from an initial claim that the capacity for a thriving society lies both in individuals and the collective, as an emerging "field of possibility" (Scharmer, 2018). We can access this field of possibility as we collectively co-create our future. 


\section{Embodied Forms of Knowing}

In this paper, as we consider direct subjective experience as valid research data, we must investigate the knowing inherent in perceptual experience and look closely at the fundamental characteristics of our "being-in-the-world" (Heidegger, 1962). To begin with, we must first acknowledge our embodied experience- the first-person experience of living in a body. Social Presencing Theater (SPT) is an awareness-based social art form developed at the Presencing Institute to support organizational and systemic change. SPT reveals that usually we do not recognize how much leverage and power for transformation lies in our very ordinary embodied presence. Our embodied knowing is mostly non-verbal. For us, embracing a new paradigm of inquiry and practice means recognizing that embodied knowing is core to our experience of the world (Varela, 1991).

Being a reflective practitioner (or a practice-based researcher) means exploring and finding ways to bring scientific methods (i.e., third-person) and direct subjective experience closer together (Varela, 1991). We can no longer leave out the value of our direct experience from what it means to be, to know, to research, and to practice - as if truth were ultimately an abstract understanding of reality through theories and models. As Maturana (1987) \& Varela (1991) have posited, "everything perceived, theorized, believed, researched, and known is done so by an observer." However, it would be naive to rely on direct perception without a rigorous method. Likewise, it would be naive to disregard the value of what we know through conventional scientific observation, just because we are (i.e., personal and reflexive). "Being-in-the-world" has fundamental significance even before any sense or meaning is attributed to the worlds we inhabit (Merleau-Ponty, 1945, 2012) or enact (Varela, 1991).

As individuals, we make up social groups and systems. There is no escape from being a part of something larger than ourselves. Therefore, we frame our inquiries using the lens of the collective: first, looking at the organizing structures of the social system (Meadows, 2008) and second, at the felt and relational qualities of the system, what we refer to as a social field. Social field is a term defined by Otto Scharmer (2018) in the book Essentials of Theory $U$ as a "quality of relationships that give rise to patterns of thinking, conversing and organizing" (p. 14)—i.e., the relational, felt dimensions of our social systems.

\section{Artful Forms of Knowing}

For this article, we draw from two case studies using a combination of two art-led forms of investigation as the primary means for participants to frame, experience, reflect, and apply insights from their embodied experience. The artsled methods include a combination of performing arts (Social Presencing Theater) and awareness-based design prompts. Here, we define awareness-based design prompts as non-intrusive, tangible artifacts primarily focused on sensing for something in a particular environment, seeking to uncover information, and encouraging open inquiry without necessarily being goal-oriented. These design- 
led tools have mostly been used as a means to ground reflection in tangible artifacts produced by (or with) workshop participants- using, for example, photographs, video, and drawing.

We recognize the value of being able to relax into situations, to be in touch with inherent spontaneity, and to allow activities to emerge naturally from collective awareness. In the workshops referenced in this article, we have asked participants to suspend preconceived ideas and mindsets as much as possible- to open the space for something fresh to come forward. By dropping judgement and cynicism, the ground itself becomes a play of curiosity and appreciation of what others offer-the ground of creativity. This attitude is exemplified in a quote by Shunryu Suzuki (2011) who said, "In the beginner's mind there are many possibilities, in the expert's there are few" (p.21). For us, SPT is a place where practitioners cultivate a "beginner's mind."

As authors, we have rarely differentiated doing research from doing art. This has led workshop participants to question what we understand the words research and art to mean. As reflexive practitioners, we consider this work to be an integration of art, action research, and social/organizational applied contexts. As a social practice, this work is a form of artistry or performance connected with politics, aesthetics, and the creation of healthy societies. For us, art could denote a research artifact-meaning a tangible element, such as our bodies or a deck of cards with drawings; or a social process. In that way, a social process of change within a social group, organization, or system would be understood as a piece of social art, as well as a research outcome.

\section{Cultivating Embodied and Perceptual Capacities}

For this paper, our core question is: How does a more precise and granular verbal/visual language for embodied experience (using Social Presencing Theater) contribute to the activation of social systems change? A supporting question explored in this paper is: What are some examples of patterns of feeling, thinking, relating, and doing that might inform the movement choices we make within the context of exploring social field shifts? As a methodology, SPT particularly addresses the question: How might we make visible intangible aspects of our social systems? The larger intention is to develop arts- and awareness-based action research protocols that activate and make visible the deeper creative capacities of social fields (Scharmer, 2018). Awareness-based action research builds on the work of Kurt Lewin (1966) and includes the importance of the inner condition of the researcher.

SPT has its roots in Japanese traditional dance, pedestrian movement as dance, contemporary choreography, and movement theater. Hence, it engages the body as a "wider way of knowing" (Heron \& Reason, 2008) - a physical intelligence that, as whole selves we all have, but often do not attend to. As a social art form, SPT was designed to make visible deeper social patterns that support the cultivation of healthy social fields, sparking creative action in teams, organizations, and communities. For the case studies in this paper, groups of 
people have been asked to do two embodied activities: Village and Stuck. The binding factors between the Village and the Stuck activity are: first, both activities share a common aesthetic language; second, the practices are methods of training for awareness-based interventions. However, there are differences between the two. Village is an ensemble activity that explores the function of awareness in the co-creative process. Stuck is an application of awareness to personal transformation.

Both activities are used as a laboratory for cultivating perceptual capacities; learning to attend to and notice social processes. In these activities, participants go through a process of 1) engaging in the activity, 2) reflecting on their felt experiences, and 3) applying the learning by identifying insights they may take forward into their work or life contexts.

\section{Interior Capacities of Individuals}

In this paper, we frame interior capacities as the individual's ability to become aware of and to cultivate their interior condition (i.e., the inner place from which we operate) in order to be more fully equipped to engage the complex social, environmental, and spiritual issues of today. Cultivating interior capacities can mean discovering new ways to engage the heart (feeling), mind (thinking), and will (doing) to actually change deep-rooted behaviors. We reference a conceptual framework which was originally proposed by Schein (2010) as a model of organizational culture. In this paper, we particularly refer to an adapted version of this framework, the iceberg model by Scharmer (2009), as our theoretical framework for clarifying what we mean by interior capacities. The model basically states two dimensions. One is above the waterline and refers to what is visible in terms of our behaviors and actions. Below the waterline are hidden aspects of what ultimately gives rise to our behaviors, including: 1) systemic structures; 2) mental models, beliefs and mindsets (patterns of thought), emotions, and felt experience (relational patterns), and 3) source, the inner place of awareness from which we operate or create.

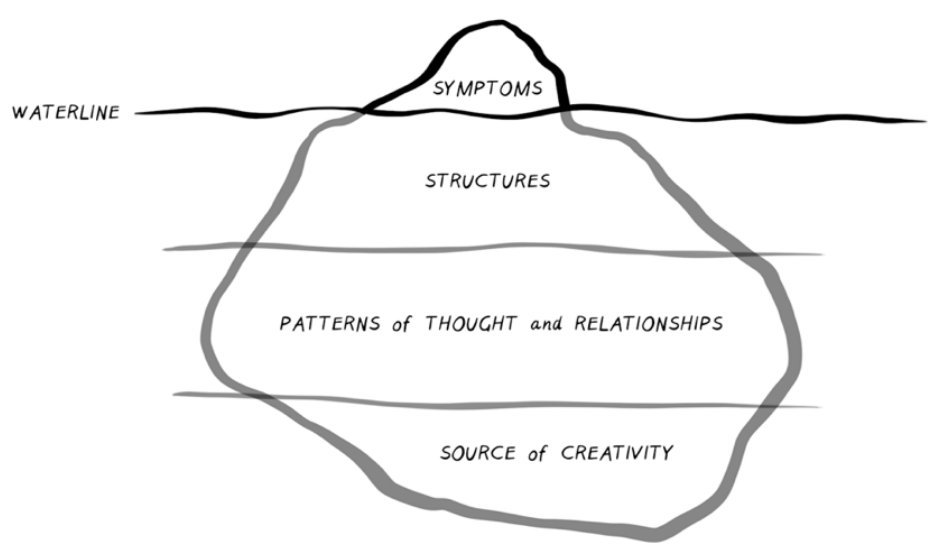

Figure 1: Iceberg Model-as adapted by Scharmer (2018) | drawing by Kelvy Bird (2020) 


\section{Exterior Capacities}

By exterior capacities, we mean the capacities of individuals to perceive what is outside of themselves: first, the visible social structure that we (Presencing Institute practitioner-researchers) call the social body; second, the interiority (i.e., felt quality) of a social system called the social field. Field Theory was originally defined by psychologist Kurt Lewin (1966) as he examined patterns of interaction and relationships between individuals and the environment (what he called Field). At the Presencing Institute, our colleague Otto Scharmer (2009) introduced us to Lewin's Field Theory when we began to articulate the term social field. By that we mean the relational qualities in a social system, i.e., the patterns of relationship and interactions among people.

Embodied activities such as the ones introduced later in this paper offer a visible microcosm of a social system. We can actually see people doing something together, which is visible (the social body). Yet the activities create a quality of relationship that is not visible, but clearly experienced and sensed. When we try to consider a larger system, for instance education, we cannot actually see the system (it is not visible in the way that a social group doing an embodied practice would be). However, even for a larger social system we can still register and tap into the felt qualities of its social field.

\section{Methodology and Case Studies}

\section{Methodology}

Our methodology uses a combination of arts-led research and awareness-based action research. Workshop participants are taken through an arc of embodied activities (as described below) using Social Presencing Theater, in particular: Village, and Stuck. Research methods include case studies, group observation, journaling, group reflection, design prompts, and iterative prototyping. The case studies draw from observations in applied situations, and learning is re-

integrated into the process through iterative prototyping. The prototypes design and introduce awareness-based prompts into group processes. These design-led tools prompt new pathways for awareness and reflection while allowing for open conversations that inform their very design iteration. Ultimately, it is our intention that our methodology explores an integration of first-person (personal/reflexive), second-person (interpersonal/relational), and third-person data (conventional scientific observation).

The reflection part is usually done in small groups of three to five people, using first-person voice ( $I$-sentences) to speak of their experience. People describe their experience using the words, "I saw...," "I felt...," "I did ....". I saw and I did describe the visible structure, including body postures and spatial choices made by the social group. For example, "I saw the group was at different levels (some on the ground and others standing)" or "I saw we moved in the same direction at a rhythmic pace." I felt describes sensations, feelings, and a relational structure, 
for example, "when you moved closer, I felt curious", or "when you released my hands, I felt surprised."

\section{Case Studies}

For this paper, we use two SPT embodied activities as case studies, observing participants from capacity-building programs delivered by the Presencing Institute (from 2017 to 2020). Workshops were designed for groups of 20-30 participants, including organizational leaders in business and non-profit sectors, educators, artists, architects, freelancers, and consultants in the fields of organizational change, personal development, learning, and ecology.

The first case study draws from a series of prototypes on developing a visual and verbal language for reflection on one's embodied experience within social groups (teams, organizations). This was developed in parallel with two advanced training programs on Social Presencing Theater (2017-19) in New York and Berlin. The second case study is the refinement of a pattern language for social fields, drawing from individual, or systemic obstacles (what we call Stuck situations) embodied by researchers and SPT advanced practitioners during two research gatherings (2019-2020) on Social Presencing Theater, in Nørre Snede (Denmark). By pattern language we mean a visual, embodied, and verbal language on patterns of "thinking, conversing and organizing" (Scharmer, 2018) within the context of social systems research. The observations and learnings from each case are introduced below. Ultimately, we surface a pattern language for social fields made up of two parts: first, an aesthetic language (i.e., language that describes the felt sense of direct experience) to reflect upon and speak about individual and collective movement and spatial choices; and second, the description of three "families" of social field archetypes. We define archetype as a recurrent pattern or feature.

We are interested in developing a fresh language to describe experience which is "aesthetic, immediate and relational" (Pilgrim, 1986). This opens a way for participants to shift from conventional subject-objective descriptions to wider perspectives. For example, in some SPT activities we invite the voice of the future to inform us. While in another practice, the group listens into what the whole social field is communicating. In these ways, language turns the subjectobject orientation around towards allowing description of experience to come from the whole (what is the whole saying to us?). That is, a shift in point of view from me (what I think) to you/it (the voice of the collective). Case study 1 explores whether an aesthetic language can support the opening of the felt sense of the collective.

\section{Case 1 | Village: An Aesthetic Language for Describing Social Field Qualities}

The Village practice was developed by choreographer Arawana Hayashi to explore the ways in which groups create coherent social structures. Participants (groups of ten to twenty people) usually begin by standing or moving around in a 
room. They are introduced to a social vocabulary including seven things they can do in the Village: stand, sit, lie down, walk, run, turn, or greet with a bow or nod. While engaged in these activities they are asked to maintain a mindful attention to their bodies and an awareness of the entire social space (both the visible structure, referred to as the social body, and the invisible relational quality, termed the social field). They explore three dimensions: level (e.g., lying down, sitting, or standing), proximity (distance to others), and direction (which way one is facing). This specific physical and spatial vocabulary affords choice-making which becomes the raw material for group exploration, reflection, and learning. For twenty minutes, people use this vocabulary to explore what they can cocreate. At the end, small groups of three to five people reflect on what they noticed, felt, or saw. From direct experience of the practice and through observing practice groups, we were able to identify 36 social patterns which were then collected into a reflection and research tool, the Aesthetic Language Cards. These begin to describe specific qualities of social fields.

\section{Case 2 | Stuck: Three Families of Social Field Archetypes}

The Stuck activity was developed by choreographer Arawana Hayashi and colleagues at the Presencing Institute. People are asked to individually embody (i.e., come into a body shape, which we refer to as Sculpture 1) a situation in their organizational life in which they feel stuck. Stuck is not framed as a problem to be solved, but rather as an opportunity to learn. People are asked to attend to their Stuck shape with careful observation. Then the person allows the body to begin a movement, which moves them out of their embodied stuck shape. The subject is relying on their embodied experience, not on their thoughts about their experience. They follow that movement until it comes to an end (Sculpture 2). They reflect on the transition from their first sculpture to the second. The research team usually participates in three ways: first, by engaging in (doing) the activity with workshop participants; second, by holding small-group (three to five people) or whole-group conversations reflecting back on experience, as described in the methodology section above; and third, by going through the artifacts (e.g., images, photos, videos) participants might have produced. For example, in the case of the Stuck practice, participants have at times taken photos of each other's embodied sculptures. In these ways, the research team has collected and studied the data that would reveal similarities and differences in stuck shapes and in the patterns of movement that shift people from their first sculpture to the second. Our findings reveal three broad archetype families of stuck patterns, which have contributed to describing a pattern language for social field transformation. 


\section{Findings: A Pattern Language for Social Field Shifts}

\section{An Aesthetic Language for Describing Social Field Qualities}

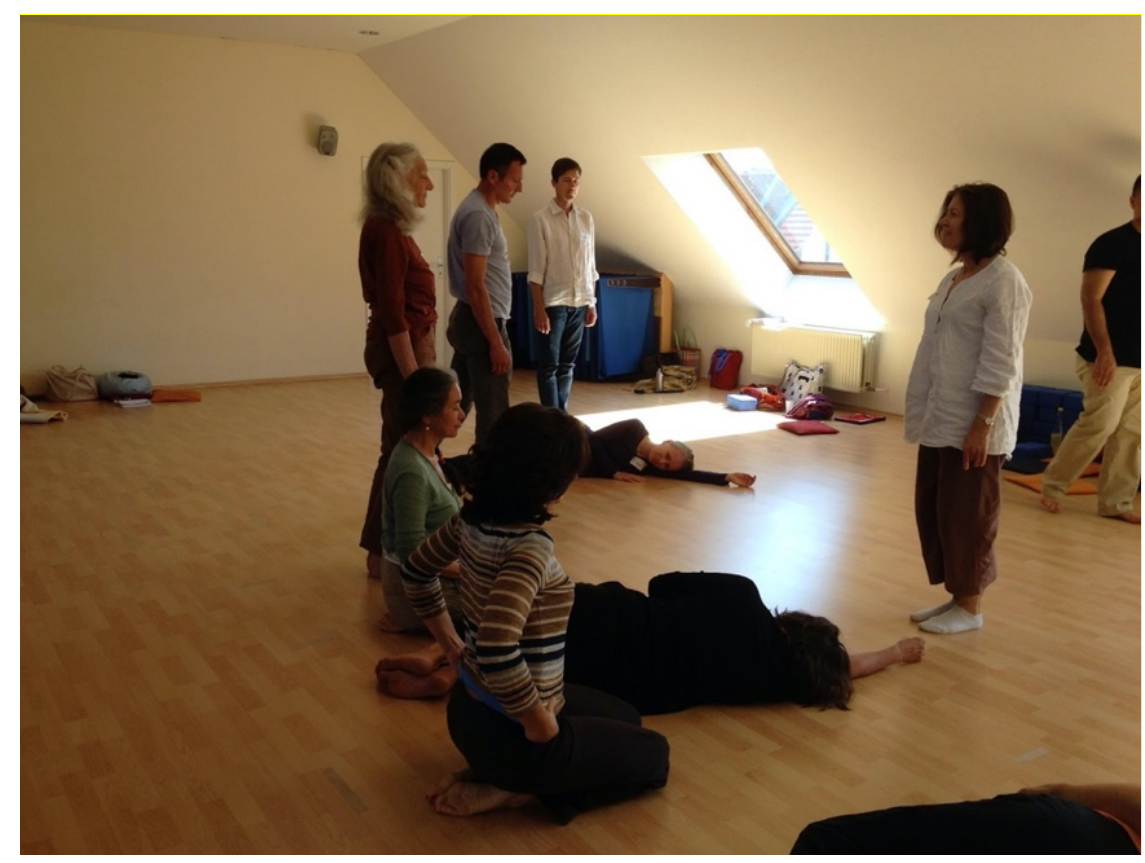

Figure 2: Village practice at the Presencing Institute

By paying attention to the groups practicing the Village, we noticed how people co-created a social reality together, either by moving the same as someone else/others, or different from someone else/others. Some people would start something new and, in doing so, lead the way. Others would follow (same as), at times mirroring or repeating a certain movement, or contrast (different than) what was offered. As these patterns repeated, we recognized them as movement and spatial choices, a demonstration of people exercising choice-making. The Village was an example of collective making, knowing-in-action (Heron \& Reason, 2008), and shaping of a micro version of the social world.

We noticed the practice offered participants a challenge: They experienced something felt, intangible, and non-verbal, while being asked to communicate verbally what that experience was. We noticed the descriptions of their experience were often habitual, interpretive (i.e., conceptual), vague (hard to follow), generalized (not specific), or psychological (sharing of personal, emotional states). These expressions often failed to reveal the multi-layered, underlying patterns and intangible qualities that were present in the social field. We wanted to draw attention to the relationship between the visible social-spatial patterns that the group enacted and the feeling quality produced by those actions. For example, when the group members made specific movement choices that were visible, they created a social field that expressed a sense of harmony. If one person introduced a rhythmic pattern by stamping, tapping, or swinging and 
others joined, rhythm became a binding pattern. These felt, intangible elements related directly to the visible social configurations and spatial patterns. We could see coherence, contrast, and rhythm happening as elements of social field creation. We began to consider these structural principles of social configuration as the beginning of a pattern language.

We drew upon the patterns we observed and introduced words to express with precision the richness of non-verbal experience. This addressed a need for more specificity (refining language), sharpening observational skills, broadening the language from habitual ways of describing experience, and including the perspective of the whole. In iterative cycles of prototyping, we drew from the performing arts and design theory (Lidwell, 2003) to create a language based on these patterns-language for what is felt. Hence, we named it an aesthetic language, aesthetic being the opposite of anaesthetic (i.e., numb), that which is felt. By introducing a first iteration of a card deck as a designed prompt for group reflection, we proposed a language that was inspired by early observations of the group practices, and also introduced principles from design theory and theater. These included: contrast, edge relationships, scale, balance, consistency, rhythm, rituals, similarity, proximity, repetition, ambiguity, motif, and symmetry. As a design prompt, the intention of using the card deck was to spark and provoke new ways of ascribing language to experience, while also testing what sticksi.e., what verbal language would make sense to practitioners to speak of their felt experience.

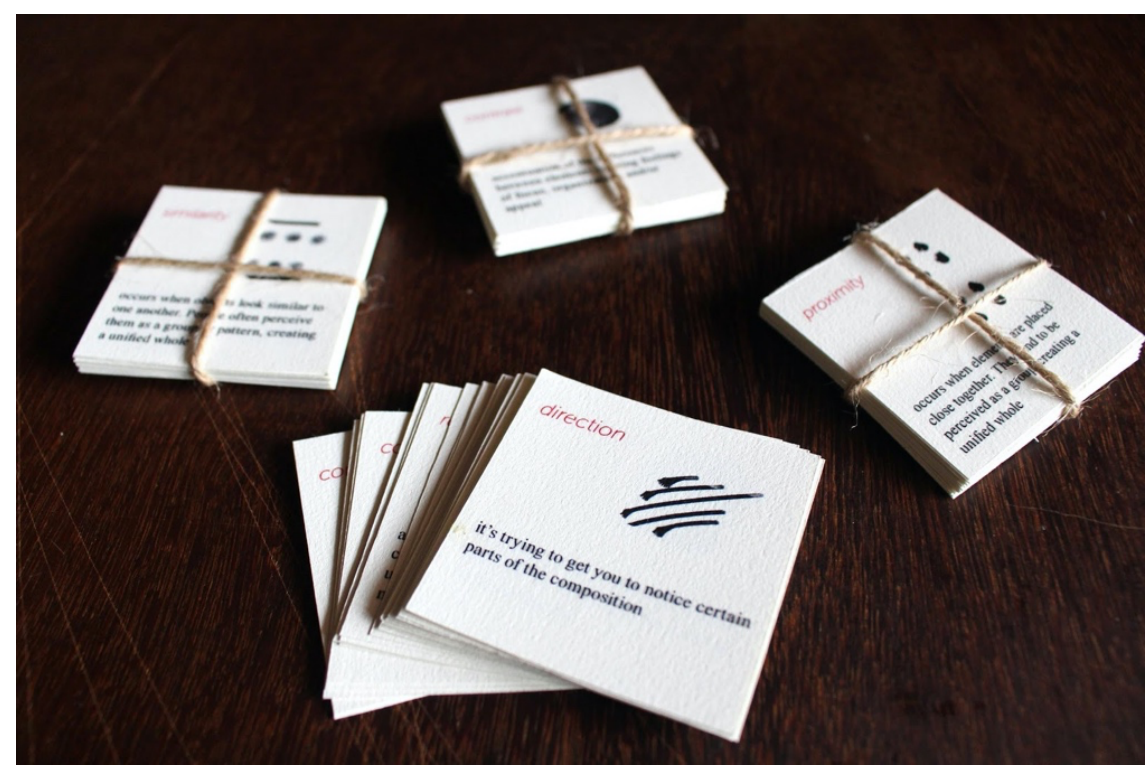

Figure 3: Printed cards as prototype 1.0 (New York, 2017)

Over time, we noticed that groups also co-created social interactions based on relational qualities (i.e., the manner in which relationships were established). By asking people why they made certain choices in the Village, they would speak of a need to belong, an interest in playfulness, a sense of curiosity, a feeling of inclusion or exclusion, connection or disconnection. We concluded that these 
principles did not belong to the category of the visible (spatial) structure, as they referred more to the group's relational experiences, i.e., how they felt in relating to one another, and the space.

contrast

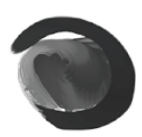

accentuation of the differences between elements creating feelings of focus, organization, and/or appeal

balance

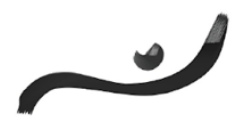

the organizing of parts in a way that suggests equilibrium, can be symmetrical or asymmetrical

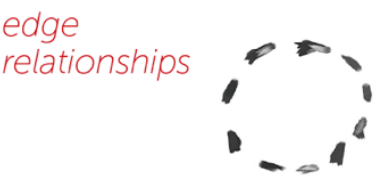

interactions at the edge of individuals, groups, spaces and systems

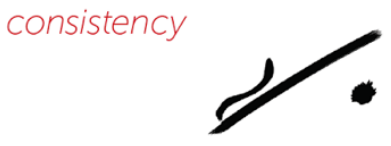

stays the same over a period of time, reliable

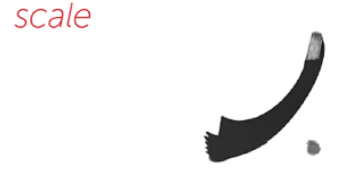

intentional variations in size or proportions

rhythm

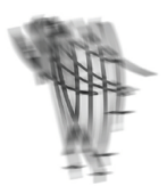

compositional flow created by a timed movement through space

Figure 4: Version 1.0 of the Aesthetic Language Cards (New York, 2017)

Another observation of the group practices revealed patterns in terms of awareness-how people were attending to themselves (i.e., the interior condition, of individuals); how they attended to others/the space (i.e., exterior conditions, as a social body); and how they attended to the emerging shifts in the social field. For instance, people would speak of how they felt tightening, tensing, or closing down to the exterior environment. Upon noticing that, they were reminded to relax, feel grounded, and look outside of themselves. We clustered these observations into a principle called relaxation. Others spoke of a soft gaze (a peripheral vision) and how at times their attention was on the whole space, including all participants or stakeholders. We named that principle attending to the whole.

Based on these observations, we categorized the new patterns into two new categories: relational structure (relational qualities) and deep structure (how people notice, attend, or are aware of their experience, and of others/space). In addition to the visible structure from the first round of prototypes, we created a second iteration of the deck of cards as an awareness-based prompt: a research tool to prompt reflection through the act of "becoming aware" (Depraz, Varela \& Vermersch, 2003). We currently understand this to be an output of a participatory research process, that included thoughtful observation, iterative cycles of prototyping, and group feedback. While the cards are a research output, 
they are also a tool for further reflection, as they continue to be used by a community of practice.

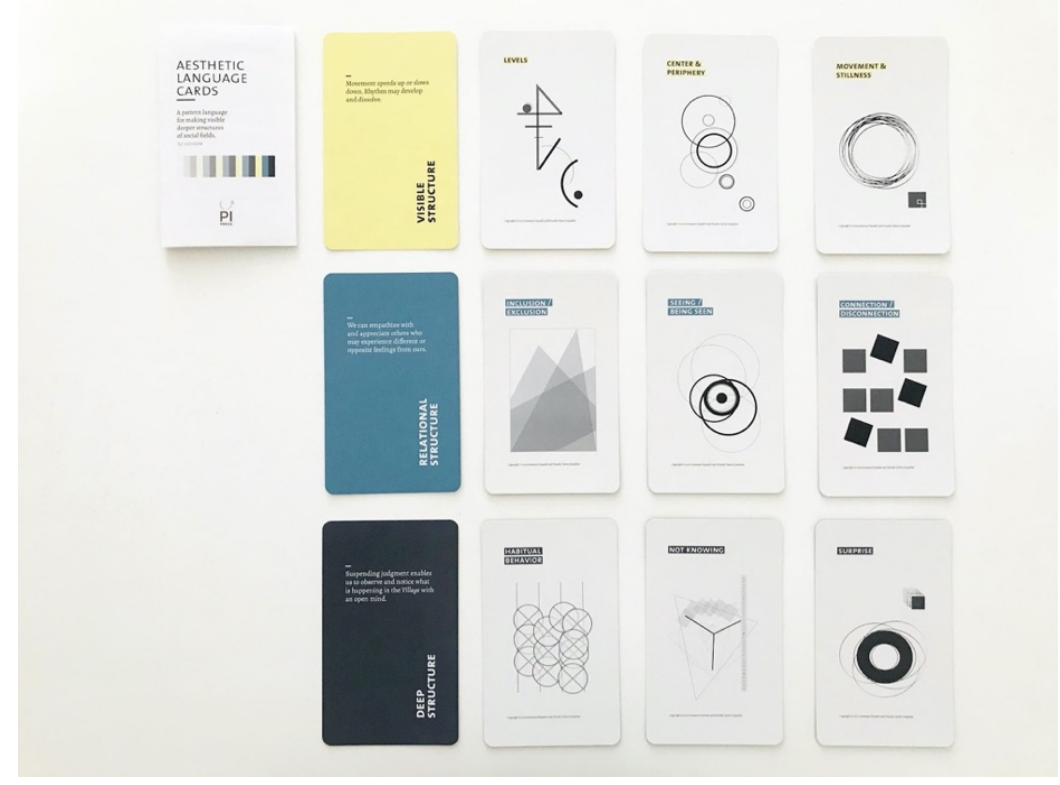

Figure 5: the version 2.0 of the Aesthetic Language Cards introducing the visible, relational, and deep structures (Berlin, 2019)

\section{Three Families of Social Field Archetypes}

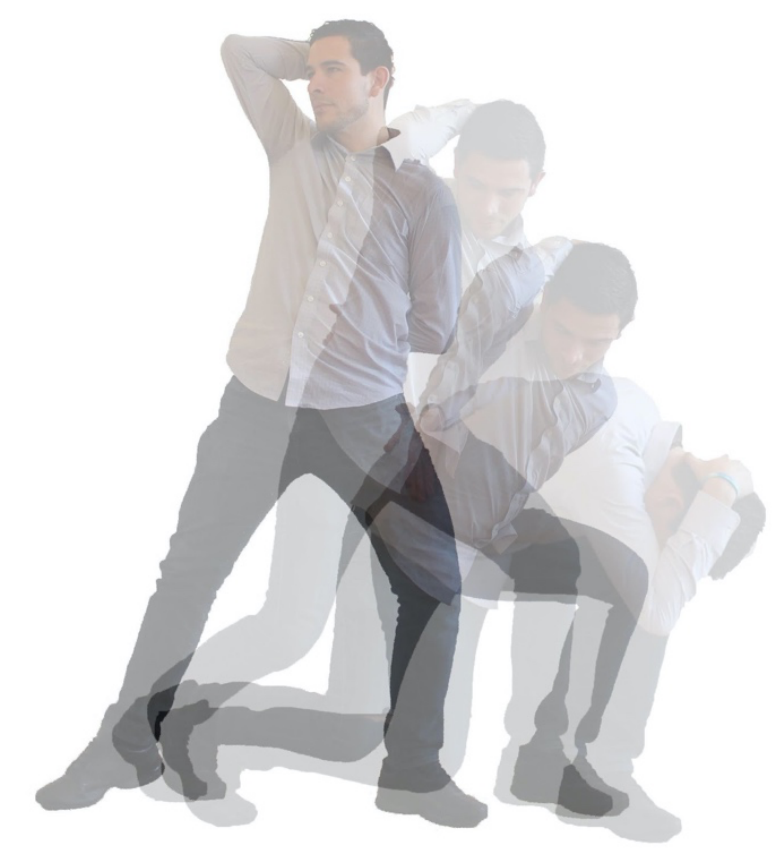

Figure 6: Movement transition during the Stuck activity (New York, 2017) 
When we observed groups using their bodies to give physical form to some aspects of a social context, organization, or system, it became clear that there are similarities and patterns where it concerns the tangible, visible elements of the social structure (i.e., the embodied physical shape). In the Stuck activity, for instance, we could see physical shapes being pushed down or arms stretched in different directions. We saw when a shape was crunching in or flat on the ground. The visible dimension of these embodied shapes is what we call the visible structure. However, stakeholders and workshop participants also spoke of felt qualities. That is, when a person's embodied shape evokes a certain feeling or sensation, both in those embodying it and in those who see it. The felt experience became the basis for an expanded feeling of connection with others or with the environment, being part of something larger than oneself, and feeling a sense of the whole. Ultimately, we observed that through the Stuck activity these embodied shapes simultaneously have both visible and felt characteristics.

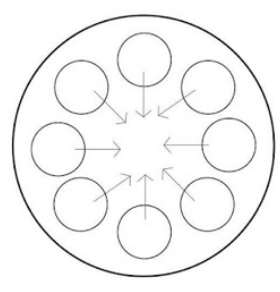

DOWN AND IN

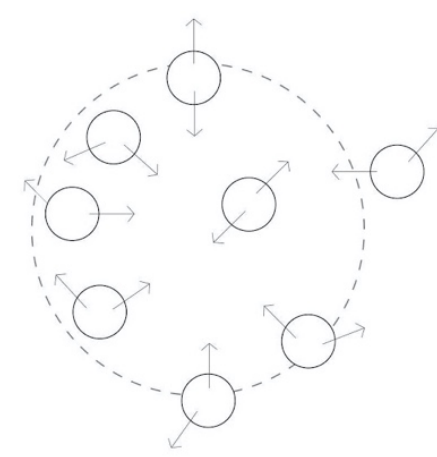

PARTS GOING IN DIFFERENT DIRECTIONS

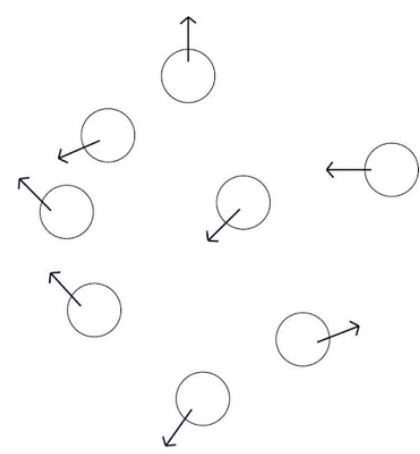

UP AND OUT

Figure 7: A scale of three archetype families identified in this case study.

In order to develop patterns for language to describe the felt experience within the context of social systems, we began observing individuals and prototyping a visual model to gather data. The photographs below convey the essence of the patterns and hint at how these patterns show up in groups. The photographs offer the reader a felt sense of the patterns. The individual is an integrated body-mind system and, given that, we are working from the premise that there are parallels between individual hindrances to creativity and collective patterns of stuckness. Therefore, observing individual practitioners gave us insight into social patterns.

We noticed that Stuck body shapes usually fell onto a continuum from what we called inward focused, when there was a very strong sense of boundary, to dispersed, when an individual's experience felt scattered, without clear edges. This scale shows an aspect of polarities. Individuals shared their stuck body shapes in groups. Based on group observation and reflection, we introduce (below) a list of the social field archetype families we have identified so far. Each contains a list of keywords people have attributed to them. We call them families 
because we realize that there is a great degree of both variability and relatedness.

Family 1, Down and In, includes physical shapes in which the body is bent down and focused inward. Usually, these shapes appeared in the sitting position, commonly curved inwards, at times with a loss of vision. Four archetypes were identified as a part of this family:

- Turned in on Itself

- Pushed Down

- No Vision

- Collapse

Family 2, Parts Going in Different Directions, introduces physical shapes in which the parts of the body were going or focused in different (usually two) directions. Two archetypes have appeared here:

- Looking Forward and Held Back

- Twisted

Family 3, Up and Out, includes physical shapes that were going in multiple directions. They were usually standing, with arms and legs stretched out, away from the center of the body. We include one archetype here:

- Going in Multiple Directions

\section{Family 1: Down and In}

Turned in on Itself: appeared at all three levels (lying down, sitting, and standing). The shoulders are hunched around the heart area, and the legs are turned in. The head is down, and the eyes are looking down. The body appears to be turning in on itself with no connection to the outside. The arms are close to the body and often legs are also close together. Words/phrases people offered: "sinking in", "looking in", "can’t see", "heart inward", "bent forward”, “crunched”, "inward focus", "pressed."

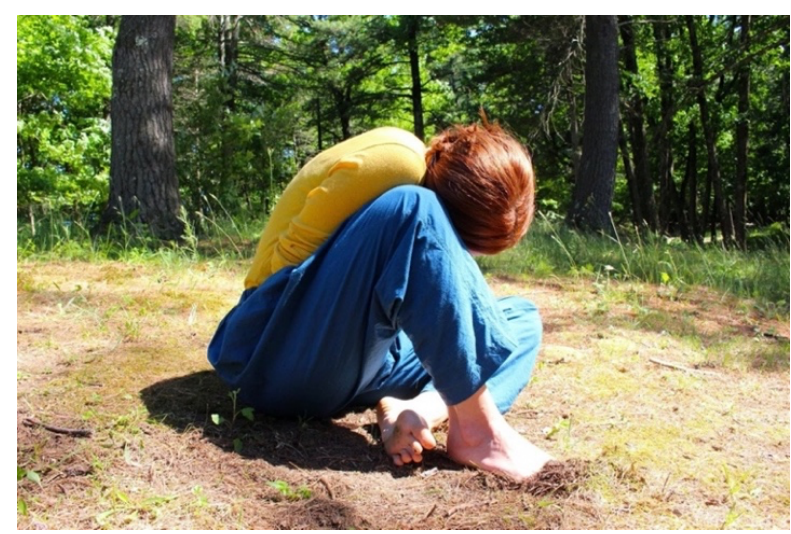

Figure 8: Embodiment of social archetype Turned in on Itself (New York, 2016) 
Pushed Down: appeared at all three levels (lying down, sitting, and standing). The body is bent over, and the spine is in a curve (C). There is a sense of weight, as if something is pushing the body down, holding it down so that it cannot straighten up. The gaze is down or the eyes are closed. The arms could be making a gesture and the legs could be wide apart or closed together.

Words/phrases people offered: "weighted down", "held down", "center but no periphery", "pulled inwards to the point there is no legs and no head", "the heart part is sunk in", "could not see or speak", "seemed to have lost their vision and voice", "not being able to get going and rise up", "crunched vertical dimension", "resilience", "powerful seed that can surface", "giving birth", "felt earth."

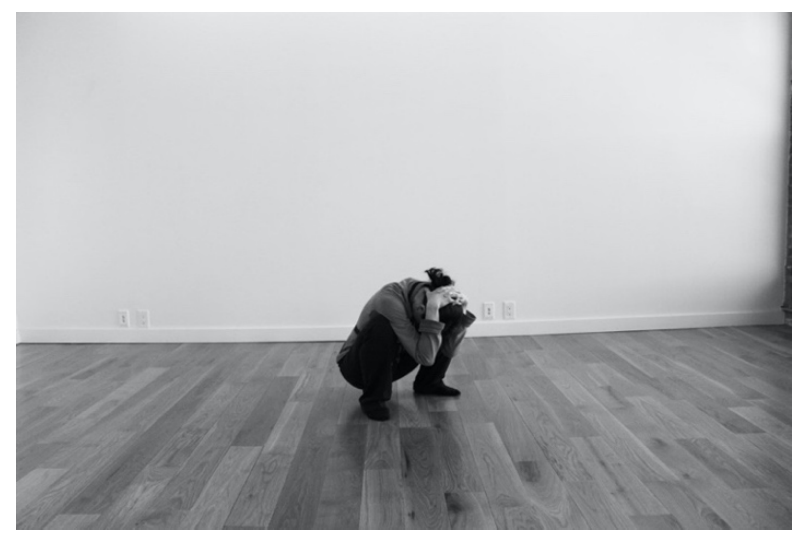

Figure 9: The embodiment of social archetype Pushed Down (New York, 2016)

No Vision: appeared in standing or sitting positions. The gesture shows hands in front of the eyes and usually, but not always, the spine is curved forward. Words/phrases people offered: "I don't know where I am going", "vertical dimension separated from the body", "head takes a bigger part", "body feels thin", "turned away", "disconnected from the ground", "connecting through the heart", "prevalent sky", "the top of the head is disconnected from the rest of the body", "the heart connects."

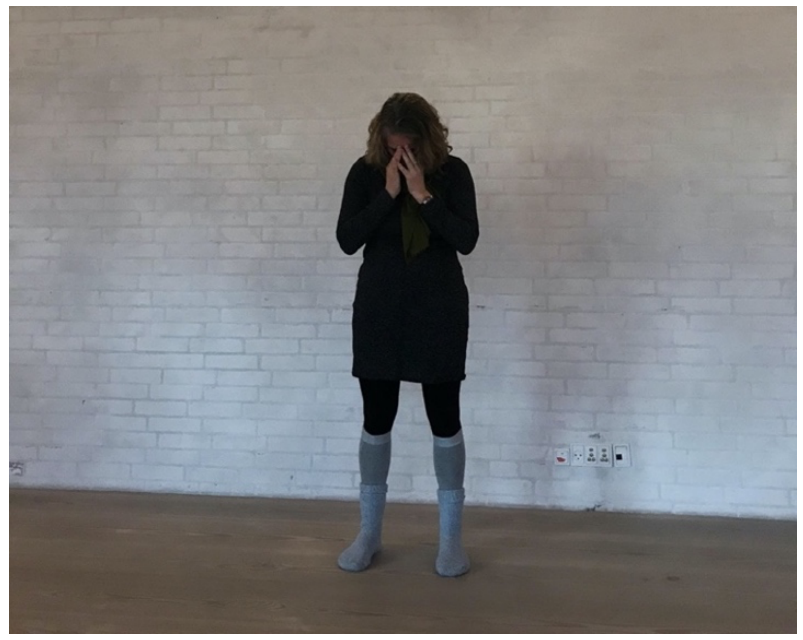

Figure 10: Embodiment of social archetype No Vision (Denmark, 2020) 
Collapse: appeared at all three levels (lying down, sitting, and standing). The body lacks energy and is in a crumpled, bent-over shape. Sometimes it is on the floor and not holding its own weight. Words/phrases people offered: "no energy", "feeling totally disempowered", "helpless", "burnout."

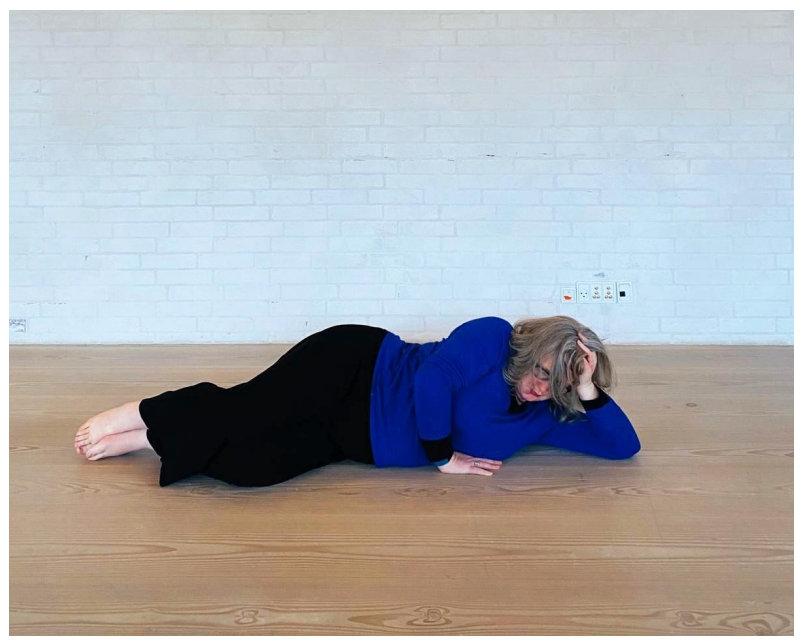

Figure 11: Embodiment of social archetype Collapse (Denmark, 2020)

\section{Family 2: Parts Going in Different Directions}

Looking Forward and Held Back: this usually appeared as a standing position. The gaze, hands, and the upper body would reach forward, while the pelvis and legs would be rooted in place, as though someone were holding them back at about the waist or hip level (some people have asked group partners to hold their "waist back", with the intention of intensifying a felt sensation). Usually, the upper and lower core parts of the body seem disconnected. Words/phrases people offered: "moving forward and held back", "disconnected parts", "significant parts are missing", "eyes forward", "with vision but not moving", "a part is moving forward and the other isn't."

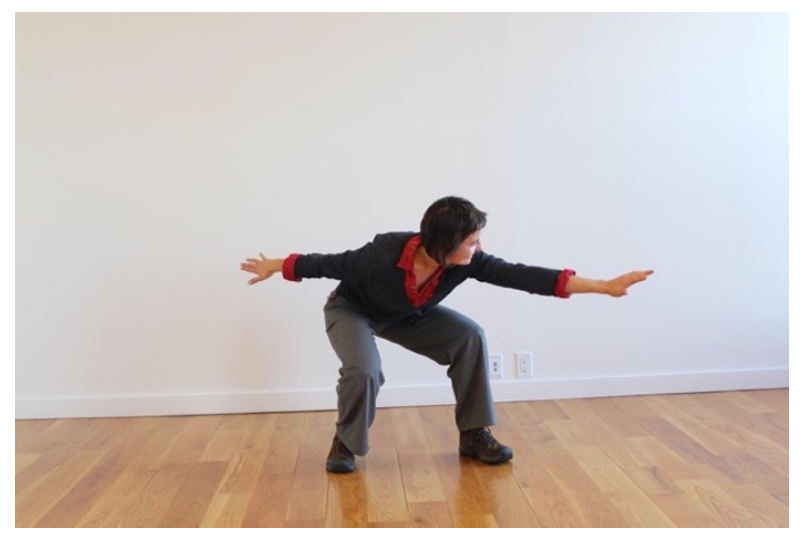

Figure 12: Embodiment of social archetype Looking Forward and Held Back (New York, 2017) 
Twisted: this social archetype was mostly seen at a standing level. The head and gaze would be facing one direction, while the lower body, feet, and legs would be pointed in another direction. Often the arms would be extended from the heart area, in a direction between the eyes and the feet. Words/phrases people offered: "one part of the body is looking in one direction and another part of the body is heading another way", "up and twisted", "spinning", "caramel twist."

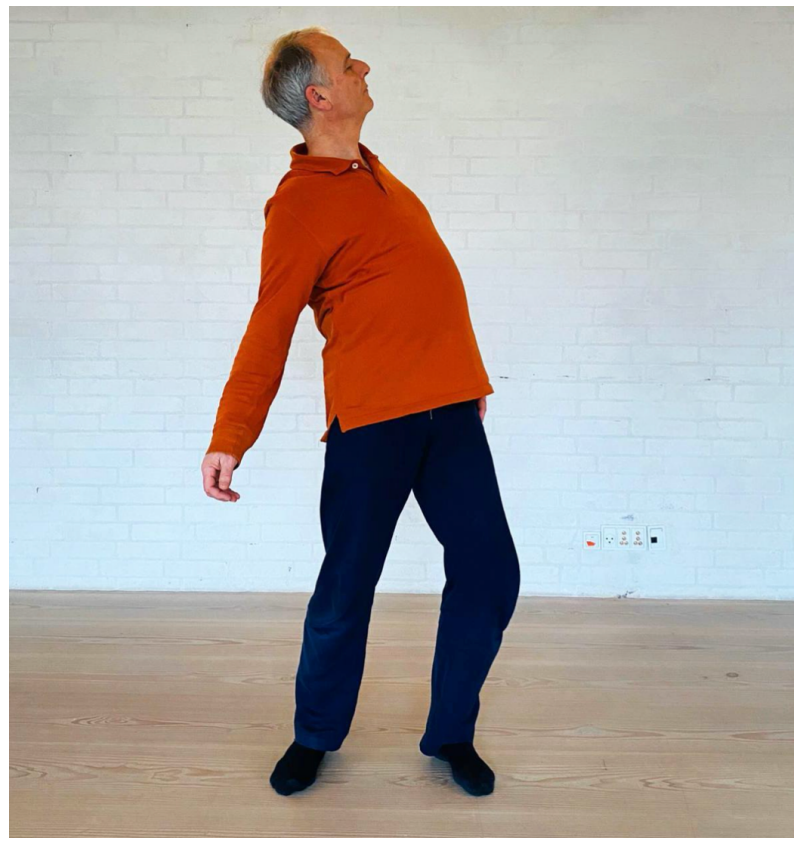

Figure 13: Embodiment of social archetype Twisted (Denmark, 2020)

\section{Family 3: Up and Out}

Going in Multiple Directions: this social archetype usually appears at a standing level. The arms are extended, as either reaching or being pulled in opposite directions. While one arm is reaching forward (or to the right/left), the other reaches backwards (or to the right/left). Sometimes one arm is touching the body while the other is stretching forward. The legs often cover a wide range. The gaze is somewhere between the arms' direction. There is tension. Words/phrases people offered: "a lot of periphery, not much center", "going in different directions", "it values spaciousness, independence, and autonomy", "may or may not be aware of others", "pulled in two directions", "feeling of loyalty to different people." 


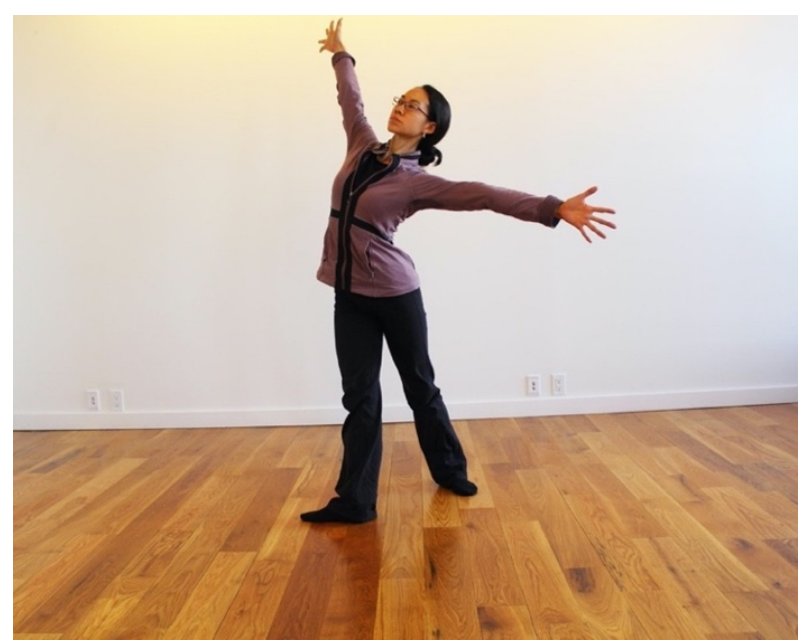

Figure 14: the embodiment of social archetype Going in Multiple Directions (New York, 2017)

The social field archetypes are not meant to oversimplify people's experience or reach some conceptual understanding. Instead, they are a framework for prompting a generative investigation into patterns through which individuals, teams, and larger systems shut down and lose access to their full potential (e.g., intelligence, compassion, brave action).

\section{Summary}

In this article, we explored how a combination of arts-led methods, including Social Presencing Theater and awareness-based design prompts, could support making visible the intangible qualities of social systems-particularly the relational dimension of social fields. By bringing Social Presencing Theater (Hayashi, 2017) and design prompts to awareness-based action research, we created a process of doing (embodied activities), reflecting on subjective experience, and identifying key actionable learnings and insights from practice.

The case studies were developed as a series of prototypes in iterative cycles over a period of two to four years. Through a practice-led research emphasis, we engaged with various stakeholders through invitation-as the embodied activities and reflection tools were gently introduced as offerings for self and group inquiry. Participants were invited to try out the methods as a way of reflectively exploring how they co-created social or organizational contexts. At the end of every workshop, the method was discussed in terms of what it revealed and what changes could be made as new iteration(s). The reflections expressed in this article are primarily from the authors' participation in the activities, from their observations of others, and from reflective dialogues with workshop participants. We, the authors, engaged both as artists and practicebased researchers.

By integrating theater (making something visible with our bodies) and design (i.e., materiality, a means of giving physical form to emergent insights and learning experiences), we arrived at an aesthetic language to describe social 
field qualities, as well as three families of social field archetypes to describe social fields (as outlined in the previous sections). The prototypes allowed us to explore possibilities for refining the language used to express embodied experience. We learned that the language helped to heighten awareness of the elements in our personal and intangible experience. Ultimately, we discovered that it allowed workshop participants to remain in a space of awareness-based spontaneity and open-ended engagement without immediately needing to interpret or make conceptual meaning of experience. By suspending the immediate need to concretize an idea or feeling, we noticed participants had more time to delve into their experience, and cultivate a sense of attention, and noticing. In the conclusion section below, we further detail our findings.

\section{Conclusion and Implications}

The objective of our research was to discover how a more precise and granular verbal and visual language for embodied experience might contribute to an activation of social systems change. To support the creation of such a language, we observed patterns of feeling, thinking, relating, and doing that inform our movement and spatial choices in the context of exploring social field shifts. By focusing on Village and Stuck as core embodied activities, a series of social patterns were revealed and clustered into the early findings of what we call a pattern language for social field shifts. This pattern language is made up of two core parts: first, an aesthetic language to describe the qualities of social fields; and second, three families of social field archetypes. Through this paper, we conclude that a more precise and granular verbal/visual pattern language for embodied experience contributes to a deeper activation of social systems change in the following five ways.

Introducing a fresh language for experience: The pattern language introduces participants to a language for embodied experience which is based on aesthetics (the felt dimension of experience) and visual imagery, as opposed to only being interpretive, relying on people's memory of what was done during the activity, or on a particular emotion. In that way, the pattern language emphasizes new forms/media of perceiving through embodiment, visual imagery, photograph, video, and drawing.

Allowing participants to stay longer with experience: The pattern language allows participants to stay longer in a process of suspension without going straight into conceptual meaning-making. The language opens a contemplative space allowing deeper reflection that accesses richer data.

Building embodied and perceptual capacities: The pattern language builds individual and collective capacity for attending to, noticing, expressing, and describing specificity of experience (e.g., focusing on specific moments of the experience by asking people to recall or evoke specific situations) and nuances (e.g., underlying patterns). 
Making transformation visible: the pattern language allows people to directly see transformation happening by embodying systemic situations and by looking at photo images across time to recall essential shifts.

Redirecting awareness: the pattern language shifts attention from selforientation to awareness of the whole. The aesthetic language helps move people from ego (talking about one's individual and emotional experience) to eco (having a sense of the whole). By helping people access the felt dimension of their experience, participants become aware of themselves as parts and co-creators of the system, rather than isolated from it.

The significance of this research is that the use of a pattern language appears to result in an increase in self-awareness, awareness of the collective, and awareness of the creative potential of the group. Social Presencing Theater activities combined with design-led methodologies reveal personal and social patterns (the movement/spatial choices), and uncover creative potential both in the individuals and in the groups. We noticed participants were more self-aware of the choices they made and the motivation for those choices.

By introducing a pattern language, this research provides a tangible knowing-for-action that might support change makers, leaders, educators, and organizations in shaping the social world of our aspirations. We recognize the urgent and pressing social and systemic challenges that individuals and organizations are facing, such as those addressed by the United Nations' Sustainable Development Goals. In our practice, we have seen that the boundaries between organizations and large social systems, and each individual's everyday life are very porous. In an expanded sense, through the performance and arts-based lens, we could say that everyday living is itself art-making. To live in society with others is to build society, or what Beuys (2004) called a "social sculpture."

By making visible more subtle and intangible aspects of our shared collective experience, we can attend to social systems transformation. This paper shows that developing design-led, arts-based, and practice-led research methods provides a fertile interdisciplinary soil to investigate the intersections between individuals and systems-between the personal and the collective. It is our hope that this intersection can be the very soil in which we can build more sustainable systems, structures, and organizations that make up social worlds we wish to be a part of.

The limitations of this study are primarily around analysis of data, particularly stuck patterns in social systems. First, we have a collection of photos and videos of individual stuck embodied shapes, but need a larger data set. Second, we are looking for ways to analyze these images. Twenty people in similar body shapes can describe their experience in diverse ways. One question for us is how to see overall patterns, while including the diversity of verbal descriptions given by participants. Another area of inquiry for further research is into how insights gained through the embodied activities and use of pattern language might be transferable to people's everyday work, family, and societal 
situations. Does the language help people embed the felt experience in ways that could be transferable to their context? Moving forward, we also ask how we might further investigate patterns of shifts in social fields. This was explored in the Village activity, but for this paper the Stuck activity focused on describing the current state of the challenge only (embodied by an individual Stuck), not the transformation into possibility. Hence, are there patterns in shifts from Sculpture one (current) to Sculpture two (emerging future)? What are those? Finally, in this paper we limited the application of the Stuck activity to an individual practice. In the future, we intend to observe stuck patterns in social groups and how groups collectively move toward innovative change. Are the patterns observed in group Stucks similar to or different from those revealed in individual Stuck practice?

The body's language is movement and stillness - a language of embodiment. When this is seen by others, social sculptures are witnessed, then the resonance between the image and the witness becomes a visual language, in the same way that looking at visual art (or any object) becomes an aesthetic, felt experience. The significance of our findings is that verbal aesthetic language can heighten the perception of felt experience and provide a verbal language for describing non-verbal experience (resonance) with more accuracy and subtlety. We opened this paper by introducing the possibility of creating a healthy and thriving society based on accessing our full creative potential. Direct knowing of, and a language for communicating, experience are necessary capacities for individuals and groups as they address today's challenges in a holistic way-engaging not only cognitive intelligence, but also the embodied, felt, or aesthetic knowing.

\section{References}

Alexander, C. (2002). The nature of order: an essay on the art of building and the nature of the universe, Book 1 - The phenomenon of life. Oxford University Press.

Alexander, C., Ishikawa, S., \& Silverstein, M. (1977). A pattern language: Towns, buildings, construction. Oxford University Press.

Beuys, J. (2004). What is art? Conversation with Joseph Beuys. Clairview Books.

Bogart, A., \& Landau, T. (2005). The viewpoints book: A practical guide to viewpoints and composition (1st ed.). Theatre Communications Group.

Cross, N. (2006). Designerly ways of knowing (1st ed.). Springer London Ltd.

Depraz, N., Varela, F. J., \& Vermersch, P. (2003). On becoming aware: A pragmatics of experiencing. John Benjamins Pub.

Goncalves, R. D. (2019, April 10). Aesthetics as a pattern language for social field shifts. Field of the Future Blog. https://medium.com/presencing-institute-blog/aesthetics-apattern-language-for-social-field-shifts-f847ce9fb2e8

Goncalves, R. D. (2019, July 17). Social reality contemplation: A performance-led approach to making visible deeper layers of social fields. Field of the Future Blog. https://www.presencing.org/news/news/social-reality-contemplation

Grocott, L. (2010). Design research \& reflective practice. [Doctoral dissertation]. ProQuest Dissertations \& Theses Global. 
Hayashi, A. (2019). Social Presencing Theater. Presencing Institute. https://www.presencing.org/aboutus/spt

Heidegger, M. (1962). Being and time. Harper \& Row.

Heron, J., \& Reason, Peter. (2008). Extending epistemology within a co-operative inquiry. In P. Reason \& H. Bradbury (Eds.), The SAGE handbook of action research (pp. 366380). Sage Publications.

Hunt, J. (2012). Letter from the editor. The Journal of Design Strategies, 5(1), 5-10. https://vizuarna.files.wordpress.com/2013/04/jds-vol5-screen-1.pdf

Janevski, A., \& Lax, T. J. (2018). Judson Dance Theater: The work is never done, by Judson Dance Theater. The Museum of Modern Art.

Kaufman, M., \& McAdams, B. P. (2018). Moment work: Tectonic theater project's process of devising theater. Vintage Books.

Knowles, J. G., Cole, Ardra L, \& ProQuest. (2008). Handbook of the arts in qualitative research: perspectives, methodologies, examples, and issues. Sage Publications.

Kolko, J. (2011) Exposing the magic of design: A practitioner's guide to the methods and theory of synthesis. Oxford University Press.

Lewin, K. (1966). Principles of topological psychology. McGraw Hill.

Lidwell, W., Kritina, H., \& Butler, J. (2003) Universal principles of design. Rockport.

Mattelmäki, T. (2005). Applying probes - from inspirational notes to collaborative insights. CoDesign, 1(2), 83-102. https://doi.org/10.1080/15719880500135821

Merleau-Ponty, M. (1945, 2012). Phenomenology of perception. Routledge.

Maturana, H.R. (1987). Everything said is said by an observer. In W.I. Thompson (Ed.), Gaia: A way of knowing. Political implications of the new biology (pp. 65-82). Lindisfarne Press.

Meadows, Donella H. \& Wright, Diana. (2008). Thinking in systems: A primer. Earthscan.

Overlie, M. (2016). Standing in space: The six viewpoints theory \& practice. FellonPress.

Petitmengin, C., Remillieux, A., and Valenzuela-Moguillansky, C. (2019). Discovering the structures of lived experience: Toward a micro-phenomenological analysis method.

Phenomenology and the Cognitive Sciences, 18, 691-730. https://doi.org/10.1007/s11097-018-9597-4

Pilgrim, R. B. (1987). Ma: A cultural paradigm, Chanoyu Quarterly - Tea and the Arts of Japan, 46.

Schein, E. H. (2010). Organizational culture and leadership (4th ed.). Jossey-Bass.

Scharmer, C. O. (2009). Theory U: Learning from the future as it emerges (1st ed.). Berrett-Koehler Publishers.

Scharmer, C. O. (2018). The essentials of Theory U: Core principles and applications. Berrett-Koehler Publishers.

Scharmer, O., \& Kaeufer, K. (2015). Awareness-based action research: Catching social reality creation in flight. In H. Bradbury (Ed.), The SAGE handbook of action research, (pp. 199-210). Sage Publications.

Schön, D. (1983). The reflective practitioner: How professionals think in action. Basic Books.

Senge, P. M. (1994). The fifth discipline: The art and practice of the learning organization. Doubleday/Currency. 
Suzuki, S. (2011). Zen mind, beginner's mind: Informal talks on Zen meditation and practice. Shambhala.

Trungpa, C. (1996). True perception: The path of dharma art. Shambhala Publications.

United Nations. (2020). Sustainable Development Goals. https://www.un.org/sustainabledevelopment/sustainable-development-goals/

Varela, F. J., Thompson, E., \& Rosch, E. (1991). The embodied mind: Cognitive science and human experience. MIT Press. 